\title{
Dual effect of insulin on plasma volume and transcapillary albumin transport
}

\author{
J.Hilsted $^{1}$ and N.J.Christensen ${ }^{2}$ \\ Department of Internal Medicine and Endocrinology, ${ }^{1}$ Hvidovre and ${ }^{2}$ Herlev University Hospitals, University of Copenhagen, \\ Denmark
}

\begin{abstract}
Summary. During the past decade it has been demonstrated that insulin, apart from its effects on metabolism and ion fluxes, has acute effects on the cardiovascular system and capillary permeability. Intravenous infusion of insulin in doses which increase plasma insulin to physiological levels, induced vascular dilatation and increased muscle sympathetic nerve activity during a euglycaemic glucose clamp. During similar conditions insulin increased the transcapillary escape rate of albumin and reduced plasma volume. Insulin has also an indirect effect on vascular permeability during hypoglycaemia, which is mediated by the increase in plasma adrenaline. Adrenaline infusion increased haematocrit and decreased plasma volume and intravascular albumin mass. In contrast to insulin adrenaline did not increase the transcapillary escape rate of albumin. Total autonomic blockade during insulin-induced hypoglycaemia abolished the increase in haematocrit, but did not influence the decrease in plasma
\end{abstract}

volume and the increase in the transcapillary escape rate of albumin. Insulin administration may also increase urinary albumin excretion, and this effect was observed during a euglycaemic clamp. The mechanism of the increase in capillary permeability after insulin has not been elucidated. A number of morphological studies indicate that insulin may have effects on endothelial cell morphology and paraendothelial cell permeability. These results indicate that insulin, apart from its effect on peripheral blood flow, may play a role in a normal transfer of macromolecules from the blood to the extracellular space after food intake. This process may be greatly disturbed in insulin-dependent diabetic patients.

Key words: Adrenaline, capillary permeability, diabetes mellitus, haematocrit, insulin, noradrenaline, plasma volume, transcapillary albumin transport, urinary albumin excretion.
Many patients with long-term diabetes mellitus show increased capillary permeability and fragility. In patients with diabetic nephropathy urinary albumin excretion rate is increased. In long-term diabetic patients leakages from retinal vessels and retinal haemorrhages are characteristic findings. Furthermore, in these patients capillary permeability to smaller ions is increased, most likely caused by structural changes in the capillary bed. During the last decade a number of studies have indicated that intravenous insulin may decrease plasma volume and increase transcapillary escape rate of albumin. In fact, insulin may decrease plasma volume by two different mechanisms. This review will briefly summarize and discuss the physiological and pathophysiological significance of these findings.

\section{Insulin and the cardiovascular system}

Several studies have shown that intravenous injection of insulin may result in a fall in arterial blood pressure in sympathectomized patients [1-3] but not in normal subjects. In diabetic patients without neuropathy insulin injection did not decrease arterial blood pressure. Plasma noradrenaline levels increased, however, even when the blood glucose concentration remained high or unchanged [4-6]. These findings have been confirmed by direct recordings of muscle sympathetic nerve activity during a euglycaemic insulin clamp in normal subjects $[7,8]$. These results indicate that an increased sympathetic nerve activity is required for blood pressure homeostasis after intravenous insulin injection. The mechanism of the hypotensive effect of insulin has not been completely elucidated [9]. It has been shown in several studies that insulin may increase peripheral blood flow especially in muscle tissue, and this may contribute to the hypotensive effect of insulin [10]. It has not been excluded, however, that insulin has a direct, stimulatory effect on sympathetic nerve activity.

\section{Plasma volume and transcapillary escape rate of albumin}

Gundersen and Christensen [11] studied the effect of insulin on plasma volume and other haemodynamic parameters in a group of diabetic patients. Blood glucose de- 
Table 1. Changes in plasma volume, haematocrit and transcapillary escape rate of albumin (TER) after insulin

\begin{tabular}{|c|c|c|c|c|c|c|c|}
\hline \multirow{2}{*}{$\begin{array}{l}\text { Authors and } \\
\text { Year }\end{array}$} & \multicolumn{2}{|c|}{ Blood glucose } & \multicolumn{2}{|l|}{ Haematocrit } & \multicolumn{3}{|c|}{ Plasma volume and TER } \\
\hline & $\begin{array}{l}\text { Normal } \\
\text { or above }\end{array}$ & $\begin{array}{l}\text { Hypogly- } \\
\text { caemia }\end{array}$ & Unchanged & Increased & Unchanged & $\begin{array}{l}\text { Decreased } \\
\text { (Plasma volume) }\end{array}$ & $\begin{array}{l}\text { Increased } \\
\text { (TER) }\end{array}$ \\
\hline $\begin{array}{l}\text { Gundersen and } \\
\text { Christensen } \\
1977 \text { [11] }\end{array}$ & $\mathrm{X}$ & & & & & $\mathrm{X}$ & $\mathrm{X}$ \\
\hline $\begin{array}{l}\text { Mackay et al. } \\
1978[12]\end{array}$ & $\mathrm{X}$ & & & $\mathrm{x}$ & & $\mathrm{X}$ & \\
\hline $\begin{array}{l}\text { Parving et al. } \\
1979 \text { [14] }\end{array}$ & $\mathrm{X}$ & & $\mathrm{X}$ & & $\mathrm{X}$ & & \\
\hline $\begin{array}{l}\text { Frier et al. } \\
1983 \text { [16] }\end{array}$ & & $\mathrm{X}$ & & $\mathrm{X}$ & & & \\
\hline $\begin{array}{l}\text { Hilsted et al. } \\
1984[17]\end{array}$ & & $\mathrm{X}$ & & $\mathrm{x}$ & & $\mathrm{X}$ & \\
\hline $\begin{array}{l}\text { Hilsted et al. } \\
1985 \text { [18] }\end{array}$ & & $\mathrm{X}$ & & & & $X$ & $X$ \\
\hline $\begin{array}{l}\text { Hilsted et al. } \\
1989 \text { [19] }\end{array}$ & $\mathrm{X}$ & & $\mathrm{X}$ & & & $\mathrm{x}$ & $x$ \\
\hline $\begin{array}{l}\text { Nestler et al. } \\
1990[22]\end{array}$ & $\mathrm{X}$ & & $\mathrm{X}$ & & & & $\mathrm{x}$ \\
\hline $\begin{array}{l}\text { Hilsted et al. } \\
1991 \text { [23] }\end{array}$ & & $x$ & & $\mathrm{X}$ & & $\mathrm{x}$ & $\mathrm{X}$ \\
\hline $\begin{array}{l}\text { + adrenergic } \\
\text { blockade }\end{array}$ & & $\mathrm{X}$ & $\mathrm{X}$ & & & $\mathrm{X}$ & $\mathrm{X}$ \\
\hline
\end{tabular}

creased from one hyperglycaemic level to a lower, but still hyperglycaemic, level after intravenous injection of insulin. Intravenous injection of insulin resulted in an unexpectedly large decrease in plasma volume and a reduction of the intravascular pool of albumin. Mackay et al. [12] confirmed these results and showed that plasma volume did not decrease after insulin administration in patients with diabetic neuropathy, thereby indicating that post-insulin hypotension was not caused by a decrease in plasma volume. Frandsen et al. [13] using microneurography showed that the increase in muscle sympathetic nerve activity after insulin administration was not abolished by plasma volume substitution.

Parving et al. [14] concluded that insulin had no effect on plasma volume and intravascular albumin, mainly because peripheral venous haematocrit did not increase after insulin. These conclusions have not, however, been supported by other investigators (Table 1).

More recent studies have shown that insulin has a dual effect on plasma volume and transcapillary escape rate of albumin, an indirect effect, which is mediated by an increase in plasma adrenaline, and a direct effect of insulin on the vascular bed (Table 1).

Insulin may also increase urinary excretion rate of albumin (Fig. 1). In preliminary experiments Hegedüs et al. [15] showed that an oral glucose load increased urinary albumin excretion in normal subjects but not in insulin-dependent diabetic patients.

\section{Effects of hypoglycaemia and adrenaline on plasma volume and haematocrit}

Insulin-induced hypoglycaemia is associated with large increments in plasma insulin as well as plasma cate- cholamines. Frier et al. [16] and Hilsted et al. [17, 18] showed that peripheral venous haematocrit increased considerably during hypoglycaemia. The increase in haematocrit was associated with a decrease in plasma volume and a large increase in transcapillary escape rate of albumin $[17,18]$.

The relative roles of insulin and catecholamines as regards these changes were subsequently elucidated [19]. Intravenous infusion of adrenaline in doses resulting in plasma concentrations corresponding to those encountered during insulin-induced hypoglycaemia caused an increase in peripheral venous haematocrit, a reduction in plasma volume and a decrease in intravascular albumin mass (calculated as plasma volume $\mathrm{X}$ plasma albumin concentration) in healthy subjects. Intravenous infusion of noradrenaline in similar doses $(6 \mu \mathrm{g} / \mathrm{min})$ caused an increase in venous haematocrit and a decrease in plasma volume, whereas intravascular albumin mass was unaffected. Neither adrenaline nor noradrenaline induced any changes in transcapillary escape rate of albumin. Thus, effects of noradrenaline and adrenaline on plasma volume size were similar, whereas the effect of these two compounds on the intravascular albumin mass was different. This is analogous to the finding that serum myoglobin concentrations decreased in response to adrenaline but not to noradrenaline [20]. In the latter study, the decrease in myoglobin concentrations during adrenaline infusion was blocked by prior beta-adrenoceptor blockade with propranolol, suggesting that myoglobin transport was a betaadrenergic mediated effect. Hence, the effect of noradrenaline seems limited to its alpha-adrenoceptor stimulating properties, e.g. a decrease in plasma volume due to increased hydrostatic pressure.

The decrease in intravascular albumin mass during adrenaline infusion may be ascribed to an increase in the 


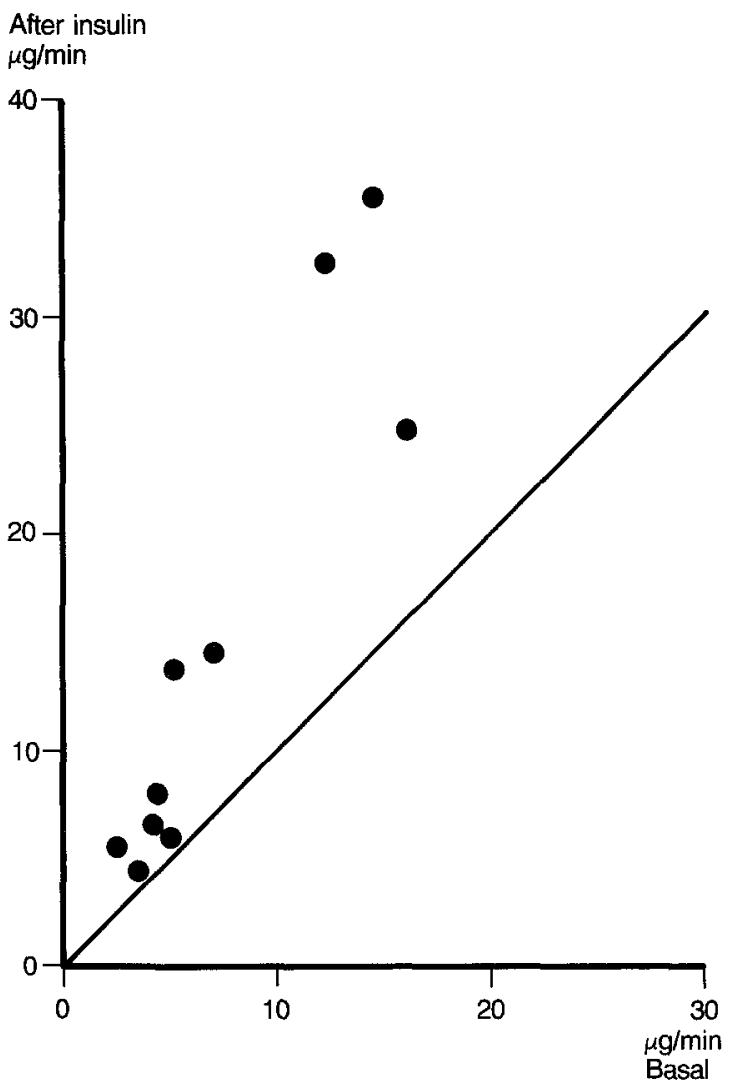

Fig.1. Urinary albumin excretion in ten normal subjects before and after insulin injection. In five subjects blood glucose was kept constant by glucose infusion whereas in five other subjects it decreased from a hyperglycaemic level to a lower but still hyperglycaemic level. The increase in urinary excretion rate of albumin was $92 \%$ and $94 \%$ above basal with declining blood glucose and constant blood glucose, respectively $(2 p<0.01)$. Reproduced from Diabetologia [30, 31] with permission

capillary surface area available for fluid exchange. This process may be reversed in haemorrhage [21].

The effect of insulin on plasma volume and transcapillary escape rate of albumin during a hyperinsulinaemic euglycaemic glucose clamp cannot be explained by elevated plasma adrenaline levels because plasma adrenaline does not increase during these circumstances. Recent studies $[19,22]$ have shown in accordance with previous findings that insulin during a euglycaemic glucose clamp resulted in a significant decrease in plasma volume, and a large increase in transcapillary escape rate of albumin, whereas the peripheral venous haematocrit did not change during these experimental conditions (Table 2). Furthermore, during pharmacological blockade with alpha- and beta-adrenoceptor antagonists during hypoglycaemia a similar pattern was observed after insulin administration [23] (Fig. 2): plasma volume decreased, peripheral venous haematocrit did not change and the transcapillary escape rate of albumin increased. These data indicate that intravenous insulin may decrease plasma volume without a concomitant increase in peripheral venous haematocrit.

Thus, the findings during hypoglycaemia may be explained by the combined effects of adrenaline and insulin. Adrenaline may increase peripheral haematocrit, de- crease plasma volume and decrease the intravascular albumin mass. Insulin has similar effects on plasma volume and the intravascular mass of albumin but in contrast to adrenaline insulin may increase the transcapillary escape rate of albumin.

\section{Mechanisms}

From the preceding discussion it is clear that insulin can decrease plasma volume by two different mechanisms: (1) indirectly by increasing plasma adrenaline during hypoglycaemia and (2) directly by a non-adrenergic mechanism which is best studied in diabetic patients during hyperglycaemia or in normal subjects during a euglycaemic glucose clamp. The first mechanism is only associated with an increase in haematocrit. This increase is mediated by an alpha-adrenergic mechanism and is due to elevated plasma adrenaline levels, which increase postcapillary resistance. The non-adrenergic mediated plasma volume lowering effect of insulin may be due to an increase in muscle capillary blood flow [24].

One of the most marked changes in haemodynamics after injection of insulin is an increase in muscle blood flow [10]. It is also well-established that microvascular haematocrit is lower than systemic haematocrit mainly due to plasma skimming. This phenomenon is flow-dependent and elevated flow rates reduce the difference between microvascular and systemic haematocrits [25]. One would therefore expect a decrease in venous and systemic haematocrit after increments in capillary or nutritive blood flow. This is not observed, probably because at the same time plasma is lost to the extracellular fluid due to the concomitant increase in capillary surface area. These two processes, which have opposite effects on venous

Table 2. Peripheral venous packed cell volume (PCV), plasma albumin, $\left(\mathrm{IVM}_{\mathrm{Alb}}\right)$ and $\left(\mathrm{TER}_{\mathrm{Alb}}\right)$ before and during infusion of adrenaline and noradrenaline and before and during hyperinsulinaemic euglycaemic glucose clamp

\begin{tabular}{|c|c|c|c|c|c|c|}
\hline & \multicolumn{2}{|c|}{$\begin{array}{l}\text { Adrenaline } \\
6 \mu \mathrm{g} / \mathrm{min}, n=6\end{array}$} & \multicolumn{2}{|c|}{$\begin{array}{l}\text { Noradrenaline } \\
6 \mu \mathrm{g} / \mathrm{min}, n=4\end{array}$} & \multicolumn{2}{|c|}{$\begin{array}{l}\text { Glucose } \\
\text { clamp }\end{array}$} \\
\hline & Before & During & Before & During & Before & During \\
\hline $\begin{array}{l}\text { Plasma volume } \\
\text { (1) }\end{array}$ & 2.801 & $2.592^{\mathrm{a}}$ & 3.328 & $3.211^{\mathrm{a}}$ & 2.951 & $2.846^{\mathrm{a}}$ \\
\hline SEM & 0.095 & 0.101 & 0.166 & 0.176 & 0.124 & 0.103 \\
\hline $\operatorname{PCV}(\%)$ & 44.2 & $45.7^{\mathrm{a}}$ & 42.8 & $44.6^{\mathrm{a}}$ & 44.9 & 45.1 \\
\hline SEM & 0.9 & 0.8 & 1.1 & 1.3 & 1.5 & 1.3 \\
\hline $\begin{array}{l}\text { Plasma albumin } \\
(\mathrm{g} / \mathrm{l})\end{array}$ & 44.8 & 44.8 & 43.6 & 45.8 & 43.5 & 42.6 \\
\hline SEM & 0.7 & 0.8 & 1.0 & 1.4 & 1.0 & 0.7 \\
\hline $\begin{array}{l}\operatorname{IVM}_{\mathrm{Alb}}(\mathrm{g}) \\
\mathrm{SEM}\end{array}$ & $\begin{array}{l}125.8 \\
5.8\end{array}$ & $\begin{array}{l}115.9^{\mathrm{a}} \\
4.0\end{array}$ & $\begin{array}{l}144.8 \\
6.6\end{array}$ & $\begin{array}{l}146.6 \\
6.1\end{array}$ & $\begin{array}{l}129.4 \\
4.2\end{array}$ & $\begin{array}{l}123.8^{\mathrm{a}} \\
4.0\end{array}$ \\
\hline $\begin{array}{l}\operatorname{TER}_{\text {Alb }}(\%) \\
\text { SEM }\end{array}$ & $\begin{array}{l}7.4 \\
0.8\end{array}$ & $\begin{array}{l}7.1 \\
1.5\end{array}$ & $\begin{array}{l}8.8 \\
0.9\end{array}$ & $\begin{array}{l}8.1 \\
1.0\end{array}$ & $\begin{array}{l}3.3 \\
1.1\end{array}$ & $\begin{array}{l}9.9^{\mathrm{a}} \\
1.3\end{array}$ \\
\hline
\end{tabular}

Reproduced from Clinical Science [19] with permission. a $p<0.05$ compared with before infusion or clamp. $\mathrm{IVM}_{\mathrm{Alb}}$, intravascular albumin mass; $\mathrm{TER}_{\mathrm{Alb}}$, transcapillary escape rate of albumin 


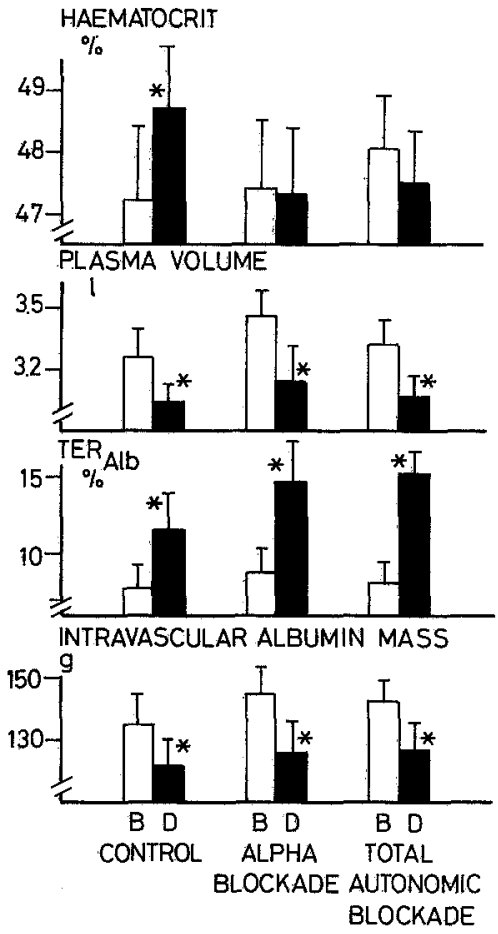

Fig.2. Peripheral venous haematocrit, plasma volume, intravascular albumin mass and transcapillary escape rate of albumin (TER aib $)$ before and during insulin-induced hypoglycaemia in six healthy males investigated with concomitant alpha-adrenoceptor blockade, with total autonomic blockade and without any blockade of the autonomic nervous system. B, Before hypoglycaemia; D, During hypoglycaemia; * Denotes significant changes $(p<0.05)$. Reproduced from Eur J Clin Invest [23] with permission

haematocrit, are related as both of them are dependent on the relative increase in capillary blood flow.

This hypothesis indicates that insulin by increasing capillary blood flow may decrease plasma volume without changing venous haematocrit. It may also explain a lack of correlation between changes in haematocrit and plasma volume observed during adrenaline infusion [19]. The haematocrit increases during adrenaline infusion due to an alpha-adrenergic mediated effect but adrenaline may also increase muscle blood flow and decrease plasma volume by the same mechanism as insulin. In the latter-mentioned study infusion of noradrenaline and adrenaline in relatively high doses $(6 \mu \mathrm{g} / \mathrm{min})$ both increased the haematocrit to approximately the same extent, but the decrease in plasma volume was twice as high during adrenaline infusion when compared to infusion of noradrenaline (Table 2). As pointed out the insulin effect on transcapillary escape rate of albumin can probably not be explained by an increase in capillary blood flow. This effect of insulin remains to be elucidated [19].

\section{Morphology}

There have been few morphologic studies of the capillary endothelium after insulin administration. In 1978 Østerby et al. [26] reported a quantitative morphologic study of the capillary endothelium of striated muscle in diabetic rats one hour after injection of insulin. The authors found that numeric density of micropinocytotic vesicles increased significantly in diabetic rats injected with insulin and thereby approached the control value. Also the ratio of free-to-attached vesicles increased significantly after insulin. McRoberts et al. [27] have recently shown that insulin may modulate the permeability of the occluding junction in T84 cell-monolayers through a receptor-mediated process. Insulin was also shown to produce similar effects on two intestinal epithelial cell lines. Interestingly, Bar et al. [28] have shown that in the perfused rat heart, insulin can differentially alter transcapillary movement of insulin-like growth factor binding proteins.

The possible relationship between insulin effects on plasma volume and transcapillary escape rate of albumin and the morphological findings after insulin administration remains to be clarified.

\section{Physiological and pathophysiological significance}

The technique of measuring transcapillary escape rate of albumin by intravenous injection of radioactive-labelled albumin is clearly not an ideal technique for studying capillary transport or permeability. Results from many different studies using different techniques indicate, however, that insulin has an effect on these parameters.

Insulin may increase muscle blood flow, sympathetic activity and transcapillary albumin transport. The increase in muscle blood flow may be important for glucose disposal after food intake but the increase in macromolecular transport remains to be explained. Hyperinsulinaemia may be associated with macrovascular disease and play a role in its pathogenesis. It should be pointed out, however, that obese subjects with normal blood glucose levels have the highest plasma insulin levels and it is mainly obese persons with fasting hyperglycaemia and lower plasma insulin levels that are considered to be at the greatest risk for the development of macroangiopathy. This suggests that relative insufficiency and/or insulin resistance may be more important [29].

It is possible that insulin may play a role in the normal transfer of macromolecules from the blood to the extracellular space after food intake apart from its effect on peripheral blood flow. This process may be greatly disturbed in insulin-dependent diabetic patients. Thus, further studies along these lines are warranted.

\section{References}

1. French EB, Kilpatrick R (1955) The role of adrenaline in hypoglycemic reactions in man. Clin Sci 14: 639-651

2. Miles DW, Hayter CJ (1968) The effect of intravenous insulin on the circulatory responses to tilting in normal and diabetic subjects with special reference to baroceptor reflex block and atypical hypoglycaemic reactions. Clin Sci 34: 419-430

3. Page MMcB, Watkins PJ (1976) Provocation of postural hypotension by insulin in diabetic autonomic neuropathy. Diabetes 25: $90-95$

4. Christensen NJ (1974) Plasma norepinephrine and epinephrine in untreated diabetics, during fasting and after insulin administration. Diabetes 23: 1-8 
5. Christensen NJ, Gundersen HJG, Hegedüs L et al. (1980) Acute effects of insulin on plasma noradrenaline and the cardiovascular system. Metabolism 29: 1138-1145

6. Rowe JW, Young JB, Minaker KL, Stevens AL, Pallotta J, Landsberg L (1981) Effect of insulin and glucose infusions on sympathetic nervous system activity in normal man. Diabetes 30 : 219-225

7. Anderson EA, Hoffman RP, Balon TW, Sinkey CA, Mark AL (1991) Hyperinsulinemia produces both sympathetic neural activation and vasodilation in normal humans. J Clin Invest 87:22462252

8. Frandsen H, Snitker S, Christensen NJ, Madsbad S, Nielsen SL (1991) Effects of human and porcine insulin on muscle sympathetic nerve activity. Diabetologia 34 [Suppl 2]: A183 (Abstract)

9. Christensen NJ (1983) Acute effects of insulin on cardiovascular function and noradrenaline uptake and release. Diabetologia 25: $377-381$

10. Liang C-S, Doherty JU, Faillace R et al. (1982) Insulin infusion in conscious dog. Effects on systemic and coronary hemodynamics, regional blood flow, and plasma catecholamines. J Clin Invest 69: $1321-1336$

11. Gundersen HJG, Christensen NJ (1977) Intravenous insulin causing loss of intravascular water and albumin and increased adrenergic nervous activity in diabetics. Diabetes 26: 551557

12. Mackay JD, Hayakawa H, Watkins PJ (1978) Cardiovascular effects of insulin: plasma volume changes in diabetics. Diabetologia $15: 453-457$

13. Frandsen H, Berne C, Fagius J, Niklasson F, Christensen NJ, Hilsted J (1989) Plasma volume substitution does not inhibit plasma noradrenaline and muscle nerve sympathetic responses to insulin-induced hypoglycaemia in healthy humans. Scand J Clin Lab Invest 49: 573-581

14. Parving HH, Noer I, Deckert T, Lassen NA (1979) Intravenous insulin has no effect on transcapillary escape rate of albumin and on plasma volume in short-term juvenile diabetics. Diabetes 28: 282-286

15. Hegedüs L, Christensen NJ, Mogensen CE, Gundersen HJG (1980) Oral glucose increases urinary albumin excretion in normal subjects but not in insulin-dependent diabetics. Scand J Clin Lab Invest 40: 479-482

16. Frier BM, Corrall RJM, Davidson NMcD, Webber RG, Dewar A, French EB (1983) Peripheral blood cell changes in response to acute hypoglycaemia in man. Eur J Clin Invest 13: 33-39

17. Hilsted J, Bonde-Petersen F, Nørgaard M-B et al. (1984) Haemodynamic changes in insulin-induced hypoglycaemia in normal man. Diabetologia 26: 328-332

18. Hilsted J, Bonde-Petersen F, Madsbad S et al. (1985) Changes in plasma volume, in transcapillary escape rate of albumin and in subcutaneous blood flow during hypoglycaemia in man. Clin Sci 69: $273-277$

19. Hilsted J, Christensen NJ, Larsen S (1989) Effect of catecholamines and insulin on plasma volume and intravascular mass of albumin in man. Clin Sci 77:149-155

20. Ljunghall S, Roxin L-E, Vinge P, Åkerstrøm G (1985) Serum myoglobin concentrations are decreased by beta-adrenergic stimulation. Eur J Appl Physiol 54:54-57

21. Hillman J (1981) Further studies on beta-adrenergic control of transcapillary fluid absorption from skeletal muscle to blood during hemorrhage. Acta Physiol Scand 112: 281-286

22. Nestler JE, Barlascini CO, Tetrault GA, Fratkin MJ, Clore JN, Blackard WG (1990) Increased transcapillary escape rate of albumin in nondiabetic man in response to hyperinsulinemia. Diabetes 39: 1212-1217

23. Hilsted J, Frandsen H, Christensen NJ, Nielsen SL (1991) Plasma volume changes during hypoglycaemia: the effect of autonomic blockade. Eur J Clin Invest 21:22-26

24. Christensen NJ, Hilsted J (1989) Insulin, plasma volume and haematocrit. Diabetologia 32: 888 (Letter)

25. Klitzmann B, Duling BR (1979) Microvascular hematocrit and red cell flow in resting and contracting striated muscle. Am J Physiol 237: H481-H490

26. Østerby R, Gundersen HJG, Christensen NJ (1978) The acute effect of insulin on capillary endothelial cells. Diabetes 27: 745-749

27. McRoberts JA, Aranda R, Riley N, Kang H (1990) Insulin regulates the paracellular permeability of cultured intestinal epithelial cell monolayers. J Clin Invest 85: 1127-1134

28. Bar RS, Boes M, Clemmons DR et al. (1990) Insulin differentially alters transcapillary movement of intravascular IGFBP-1, IGFBP-2 and endothelial cell IGF-binding proteins in the rat heart. Endocrinology 127: 497-499

29. Lebovitz HE, Vinik AI (1991) Workshop VIII - retinopathy, nephropathy, neuropathy, and tight control. Am J Med 90: 2A80S2A84S

30. Mogensen CE, Christensen NJ, Gundersen HJG (1978) The acute effect of insulin on renal haemodynamics and protein excretion in diabetics. Diabetologia 15: 153-157

31. Mogensen CE, Christensen NJ, Gundersen HJG (1980) The acute effect of insulin on heart rate, blood pressure, plasma noradrenaline and urinary albumin excretion. The role of changes in blood glucose. Diabetologia 18: 453-457

Dr. J.Hilsted

Department of Internal Medicine and Endocrinology

Hvidovre Hospital

DK-2650 Hvidovre

Denmark 